\title{
Research Paper: Comparing the Effects of Rosemary Extract and Treadmill Exercise on the Hippocampal Function and Antioxidant Capacity in Old Rats
}

\author{
Homa Rasoolijazi ${ }^{1,2,3^{*}}$ (D), Sattar Norouzi Ofogh ${ }^{3}$ (D), Shima Ababzadeh ${ }^{1,2}$ (D), Mehdi Mehdizadeh ${ }^{1,2}$ (D), Fatemeh Shabkhiz , $^{3,4}$ \\ 1. Cellular \& Molecular Research Center, Iran University of Medical Sciences, Tehran, Iran. \\ 2. Department of Anatomy, School of Medicine, Iran University of Medical Sciences, Tehran, Iran. \\ 3. Department of Neuroscience, School of Advanced Technologies in Medicine, Iran University of Medical Sciences, Tehran, Iran. \\ 4. Department of Exercise Physiology, Faculty of Physical Education and Sport Sciences, University of Tehran, Tehran, Iran.
}

\begin{tabular}{|c|c|}
\hline $\begin{array}{l}\text { Use your device to scan } \\
\text { and read the article online }\end{array}$ & dtaton: Rasoolijazi, H., Norouzi Ofogh, S., Ababzadeh, Sh., Mehdizadeh, M., \& Shabkhiz, F. (2021). Comparing the Effects \\
\hline apripa & $\begin{array}{l}\text { of Rosemary Extract and Treadmill Exercise on the Hippocampal Function and Antioxidant Capacity in Old Rats. Basic and } \\
\text { Clinical Neuroscience, } 12(3), 361-372 \text {. http://dx.doi.org/10.32598/bcn.12.3.2139.1 }\end{array}$ \\
\hline 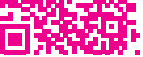 & doi http://dx.doi.org/10.32598/bcn.12.3.2139.1 \\
\hline
\end{tabular}

Article info:

Received: 26 Oct 2019

First Revision: 15 Nov 2019

Accepted: 07 Apr 2020

Available Online: 01 May 2021

Keywords:

Cognition, Antiox idant, Enzymes, Aerobic exercise, Aging

\section{ABS TRACT}

Introduction: A sequence of time-dependent changes can affect the brain's functional capacity. This study aimed at investigating the effects of Forced Aerobic Exercise (FAE) versus the Rosemary Extract (RE) on the learning abilities and oxidative stress modulation in rats.

Methods: Young and old rats received daily FAE and RE for 3 months. Using the Passive Avoidance (PA) test, we evaluated the learning and memory of the rats by Step-Through Latency (STL) score. We measured the Superoxide Dismutase (SOD), Glutathione Peroxidase (GPx), Catalase (CATA), Malondialdehyde (MDA) enzymes levels, and Total Antioxidant Capacity (TAC) in the hippocampus

Results: FAE could significantly increase the STL score $(\mathrm{P}<0.001)$ among old rats similar to the rosemary extract consumption. The SOD, GPx, and CATA enzyme activities and the level of TAC significantly increased by the treatments (exercise: $\mathrm{P}<0.001$ for SOD and TAC and $\mathrm{P}<0.05$ for CATA, exercise/rosemary: $\mathrm{P}<0.001$ for all enzymes, and rosemary: $\mathrm{P}<0.01$ for SOD and TAC). Furthermore, the MDA level significantly decreased by the treatments (exercise and exercise/rosemary: $\mathrm{P}<0.001$, rosemary: $\mathrm{P}<0.01$ ). The partial Pearson test revealed the significant positive correlations between the score of STL (day 2) with the SOD $(\mathrm{P}<0.01)$ and TAC $(\mathrm{P}<0.05)$ levels and negative correlations between the MDA level and STL score in both days $(\mathrm{P}<0.05$ for the first day and $\mathrm{P}<0.001$ for the second day).

Conclusion: Similar to the rosemary extract, FAE could increase the working memory and antioxidants activity in old rats in 3 months. 


\section{Highlights}

- Working memory scores, antioxidants activity (superoxide dismutase, glutathione peroxidase, and catalase), and the level of total antioxidant capacity in old rats were lower, but the level of malondialdehyde was higher in young animals.

- Rosemary extract administration to old rats could modulate all scores in memory and enzyme activity, except catalase and glutathione peroxidase activity.

- Exercise could modulate all scores in memory and enzyme activity, except glutathione peroxidase activity in old rats.

- Both rosemary and exercise could modulate all scores in memory and enzyme activity in old rats.

- Scores of working memory showed positive correlations with superoxide dismutase and total antioxidant capacity and a negative correlation with malondialdehyde level.

\section{Plain Language Summary}

Treadmill aerobic exercise and also consumption of rosemary extract for a long time could protect the hippocampal neurons from the destructive effects of oxidative stress caused by aging and help the memory function in male aged rats. These effects are shown by a learning and memory test (shuttle box) and some of important anti-oxidative enzymes.

\section{Introduction}

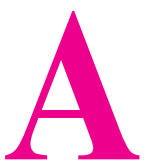

ging is often accompanied by cognitive and memory decline and an increased risk of neurodegenerative disorders (Hung, Chen, Hsieh, Chiou \& Kao, 2010; Mattson \& Magnus, 2006; Shi, Buffenstein, Pulliam \& Van Remmen, 2010). By aging, neurogenesis in the brain reduces rapidly, the neuronal function decline (Zhu et al., 2014), and the molecular oxidative stress products can accumulate (Sharman et al., 2007). The brain contains large amounts of iron and ascorbate, which are associated with lipids' peroxidation, and because the neurons are mainly post-mitotic cells, oxidative injuries accumulate in them (Lau, ShukittHale \& Joseph, 2005; Head, 2009). The theory of free radicals' role in the aging process suggests that dysfunction of the mitochondrial electron transport chain can increase superoxide synthesis and relevant Reactive Oxygen Species (ROS) (Newgard \& Sharpless, 2013). The concentration of free radicals during normal oxygen metabolism may be restricted physiologically by various cell sources of antioxidants (Chen et al., 2008).

Among the herbals, rosemary (Rosmarinus officinalis) is one of the most widely commercialized plants (Zheng \& Wang, 2001), containing the natural antioxidants, rosmarinic acid, carnosol, and carnosic acid (Zhang et al., 2012). An experimental study showed that rosemary could ameliorate the toxic effects of kojic acid in rats' hippocampus
(Naderali, Nikbakht, Ofogh \& Rasoolijazi, 2018) [Naderali, 2018 \#5]. Antioxidants in rosemary leaves demonstrated antioxidant properties in Alzheimer Disease (AD) animal model (Azad, Rasoolijazi, Joghataie \& Soleimani, 2011) and neuroprotective effects on the neuronal population involved in cognitive abilities (de Oliveira, 2018). Also, it scavenges singlet oxygen, hydroxyl radicals as well as lipid peroxyl radicals and protect biological membranes (Munné-Bosch \& Alegre, 2001).

Exercise can have beneficial effects on the cardiovascular, pulmonary, musculoskeletal, and central nervous systems (Bernardi et al., 2013) and enhances the antioxidants enzyme activity in the brain (Perry et al., 2018). It is believed that the valuable effects of running on mood and cognition may result from its role in the increase of neurogenesis in the hippocampus (van Praag, 2008). Although exercise has both preventive and therapeutic effects on depression, the related mechanisms are poorly understood (Cotman, Berchtold \& Christie, 2007). The hippocampus plays important roles in cognition, mood regulation, stress responses, learning, memory, and even predicting future events (Balu \& Lucki, 2009).

Therefore, according to our hypothesis, exercising and rosemary extract simultaneously can have synergistic effects on the antioxidant system potency of the brain and thereby improving cognitive functions. So, this research aimed to investigate the effects of forced aerobic exercise with rosemary extract administration on 
memory function in young and old rats. We have also investigated how these treatments affect antioxidant capacity levels in the brain. In this regard, we chose Catalase (CATA) (a common and vital enzyme that protects neurons from oxidative damage), Superoxide Dismutase (SOD) (the vital enzyme involved in oxygen metabolism that converts superoxide radicals to oxygen or hydrogen peroxide), Glutathione Peroxidase (GPx) (the enzyme family that plays its protective role through metabolizing the lipid hydroperoxides), Total Antioxidant Capacity (TAC) and Malondialdehyde (MDA) (the fatty acid oxidation products) enzymes (Head, 2009).

\section{Methods}

\subsection{Study animals}

One hundred male Wistar rats were used in this study. The rats were obtained from the Iran University of Medical Sciences (IUMS), Tehran, Iran. They were kept in laboratory cages ( 3 animals per cage). Food and water were freely available. The rats were kept in a room with a 12:12 hour light-dark cycle and a constant temperature of $21 \pm 2^{\circ} \mathrm{C}$. The animal experiments were carried out according to the Ethics Committee of IUMS (Ethical code number: IR.IUMS.REC.1393.24834) for the care and use of laboratory animals (following the National Institutes of Health Guide for Care and Use of Laboratory Animals: NIH Publication 1996). The efforts were made to minimize unnecessary pain and suffering within labs.

The rats were divided into old (18 months) and young ( 2 months) age groups (50 rats in each group). These 2 age groups were further divided into 5 subgroups: intact, vehicle, exercise, rosemary, and combination of exercise and rosemary (exercise/rosemary). The animals in the intact group remained in their home cages throughout the experiment. The vehicle group spent $10 \mathrm{~min}$ on a turned-off treadmill and received $1 \mathrm{~mL}$ of distilled water orally (via animal-feeding incubation needles: Perfecta, Germany) per day. Other animals received $1 \mathrm{~mL}$ rosemary extract or distilled water orally per day and underwent Forced Aerobic Exercise (FAE) using a treadmill or placed on a turned-off one for 12 weeks ( $5 \mathrm{~d} / \mathrm{wk}$ ). Hydroalcoholic rosemary leaves extract was purchased from Hunan Geneham Biomedical Technological Co. (Batch Number: RAP20-11040, China). According to a defined concentration $(100 \mathrm{mg} / \mathrm{kg})$, the extract was suspended with distilled water (Pérez-Sánchez et al., 2014). The dose of the extract was determined by using the results of previous studies (Sotelo-Félix et al., 2002).

\subsection{Forced Aerobic Exercise (FAE)}

Before starting the main exercise procedure, the rats were trained to run using a motor-driven treadmill (Pishroo Andisheh Sanat Engineering Co. Tehran, Iran) at a speed of $10 \mathrm{~m} / \mathrm{min}$ for one week. Then the main exercise procedure continued for 3 months, using the same treadmill. On the first day of trial, the animals were forced to run $12 \mathrm{~m} / \mathrm{min}$ on the treadmill for 10 minutes. Then, in the following days, both the time and the speed were increased slowly. Thus, during the $12^{\text {th }}$ week, the rats would have to run at the speed of $22 \mathrm{~m} / \mathrm{min}$ for 1 hour per day.

\subsection{Passive Avoidance (PA) test}

Shuttle box apparatus was used for Passive Avoidance (PA) (Hirsh, 1974) to evaluate short-term and working memories. The shuttle box included two compartments of the same size and a sliding door between the two compartments. The floor was made by a metal grid, which was used for delivering brief electric foot shock. A light bulb does electric lighting of one compartment, whereas the other compartment remained dark. PA included two phases: the training and the test. The two phases were performed in two following days. In the training session, we placed each animal in the light compartment and far from the door. By rat entering the dark compartment, we closed the sliding door promptly, followed by delivering a foot shock of $0.5 \mathrm{~mA}$ by the grid floor within two seconds. The test phase was done by locating the rat in the light compartment again for entering the dark part (no shock was applied) (Silva, Felicio \& Frussa-Filho, 1999). We recorded the period of entering the dark chamber; the animals were allowed a maximum of 300 seconds to enter the dark compartment.

\subsection{Tissue preparation}

After 3 months of treatment and exercise, the animals were anesthetized via intraperitoneal injection of ketamine $(150 \mathrm{mg} / \mathrm{kg})$ and xylazine $(15 \mathrm{mg} / \mathrm{kg})$ mixture, and then their brains were quickly removed from the skull. The brains were washed with cold saline phosphate buffer. The hippocampus was isolated, and after determining its weight, it was mixed with $\mathrm{pH} 7.4$ coldTris buffer $(10 \mathrm{mmol} / \mathrm{L})$ with a proportion of $10 \% \mathrm{~W} / \mathrm{V}$ and homogenized for 3 minutes, then centrifuged at 8500 $\mathrm{rpm}$ for $25 \mathrm{~min}$, at $2^{\circ} \mathrm{C}$. The produced supernatant was used for analyzing the activity or level of the enzymes. 


\subsection{Biochemical analyses}

\subsubsection{Superoxide Dismutase (SOD)}

The assay of Misra and Fridovich was employed to evaluate SOD enzyme activity (Misra \& Fridovich, 1972). We added ice-cold ethanol $(0.25 \mathrm{~mL})$ plus chloroform $(1.5 \mathrm{~mL})$ to the diluted supernatant (using $0.5 \mathrm{~mL}$ of distilled water) $(0.5 \mathrm{~mL})$ as mentioned before. After centrifugation at $3000 \mathrm{rpm}$ for $5 \mathrm{~min}$, the supernatant $(0.5$ $\mathrm{mL}$ ) was mixed with carbonate buffer $(1.5 \mathrm{~mL})$ and Ethylenediaminetetraacetic Acid (EDTA) $(0.5 \mathrm{~mL})$. Ultimately, after adding $0.4 \mathrm{~mL}$ of adrenaline solution $(3 \mathrm{mmol} / \mathrm{L})$, the optical absorption was evaluated at $480 \mathrm{~nm}$ per minute. The enzyme activity was shown as $\mathrm{U} / \mathrm{mg}$ protein.

\subsubsection{Glutathione Peroxidase (GPx)}

GPx enzyme activity (at $37^{\circ} \mathrm{C}$ ) was investigated based on the method proposed by Wheeler et al. in 1990 (Wheeler, Salzman, Elsayed, Omaye \& Korte Jr, 1990). The reaction solution was contained the following chemical compounds: $\mathrm{H}_{2} \mathrm{O}_{2}(0.2 \mathrm{mM})$, Glutathione (GSH) (1 $\mathrm{mM})$, glutathione reductase (0.14 units), Nicotinamide Adenine Dinucleotide Phosphate (NADPH) (1.5 mM), sodium azide $(1 \mathrm{mM})$, and $0.1 \mathrm{~mol}$ of phosphate buffer. In this method, the glutathione reductase enzyme catalyzes the conversion of GSH to oxidized NADPH. Then the optical absorption was measured at $340 \mathrm{~nm} / \mathrm{min}$ via spectrophotometer. GPx enzyme activity is also shown as $\mathrm{U} / \mathrm{mg}$ protein.

\subsubsection{Catalase}

Catalase (CATA) enzyme activity was measured by the Aebi method (Aebi, 1984). Twenty microliters of diluted supernatant (100 times) were added to $980 \mu \mathrm{L}$ of hydrogen peroxide solution (Distilled water $[30 \mu \mathrm{L}]$, Tris- $\mathrm{HCl}$ buffer [PH: 8; $\left.50 \mu \mathrm{l}], \mathrm{H}_{2} \mathrm{O}_{2}(10 \mathrm{mmol} / \mathrm{L})\right] . \mathrm{H}_{2} \mathrm{O}_{2}$ substrate decomposition rate was measured at a wavelength of $240 \mathrm{~nm}$ with a spectrophotometer. CATA enzyme activity is shown as $\mathrm{U} / \mathrm{mg}$ protein.

\subsubsection{Total Antioxidant Capacity (TAC)}

TAC was assessed according to the ABTS + radical cations absorption, which was described by Miller (Miller, Rice-Evans, Davies, Gopinathan \& Milner, 1993). Reducing optical absorption was measured using spectrophotometry and expressed as g/dL BSA.

\subsubsection{Malondialdehyde (MDA)}

The level of MDA was measured according to the Satoh method (Kei, 1978) to determine the lipid peroxidation level in the hippocampus. For this purpose, supernatant (see "Tissue Sampling") and Trichloroacetic Acid (TCA) were mixed with thiobarbituric acid and warmed up with sodium sulfate $(2 \mathrm{~mol})$ in a bain-marie for 20 min. The resulting chromogenic color product was extracted by n-butyl alcohol, and then the absorption of the soluble phase was read by spectrophotometry at an optical absorption rate of $530 \mathrm{~nm}$. MDA level is expressed as $\mathrm{nm} / \mathrm{mg}$ protein.

\subsection{Statistical analysis}

Values are shown as means \pm Standard Error of the Mean (SEM). R statistical software package (version: 3.5.2) was used for data analysis. We used Multivariate Analysis of Variance (MANOVA) and Turkey's post hoc test to investigate the effect of independent variables (age and treatment groups) on dependent variables (Step-Through Latency [STL], enzyme activity levels, TAC, and MDA levels). The partial Pearson correlation (control for age and treatment groups) was used to measure the impact of each independent variable as well as the interaction between two independent variables. All $p$ values were Bonferroni adjusted.

\section{Results}

Since the data of the intact and vehicle groups in all tests did not show any significant difference, we presented these two groups as a single control group.

\subsection{Passive Avoidance (PA) test}

As explained before, this experiment was performed in 2 sessions: the training session on the first day (day one) and the test session on the second day (day two), which represents Step-Through Latencies (STL).

In the first step, we evaluated the effects of age and treatment as two distinct factors, which affect animal performance on a PA task. As shown in Figure 1, statistical analysis demonstrated that neither age nor treatment affects animals' STL on the first day. While on the second day, both age $(\mathrm{P}=2.88 \mathrm{e}-05)$ and treatment $(\mathrm{P}=2.09 \mathrm{e}-06)$, alone or in combination (age group $\times$ treatment), influence the animal performance. The highest effect size was considered for the age group $\times$ treatment $(\mathrm{P}=0.05 \mathrm{e}-11)$. Also, independent variables of age $\left[\mathrm{F}_{2,87}=12.5418, \mathrm{P}<0.001\right]$ and treatments $\left[\mathrm{F}_{8,176}=4.4206, \mathrm{P}<0.001\right]$ alone or in com- 


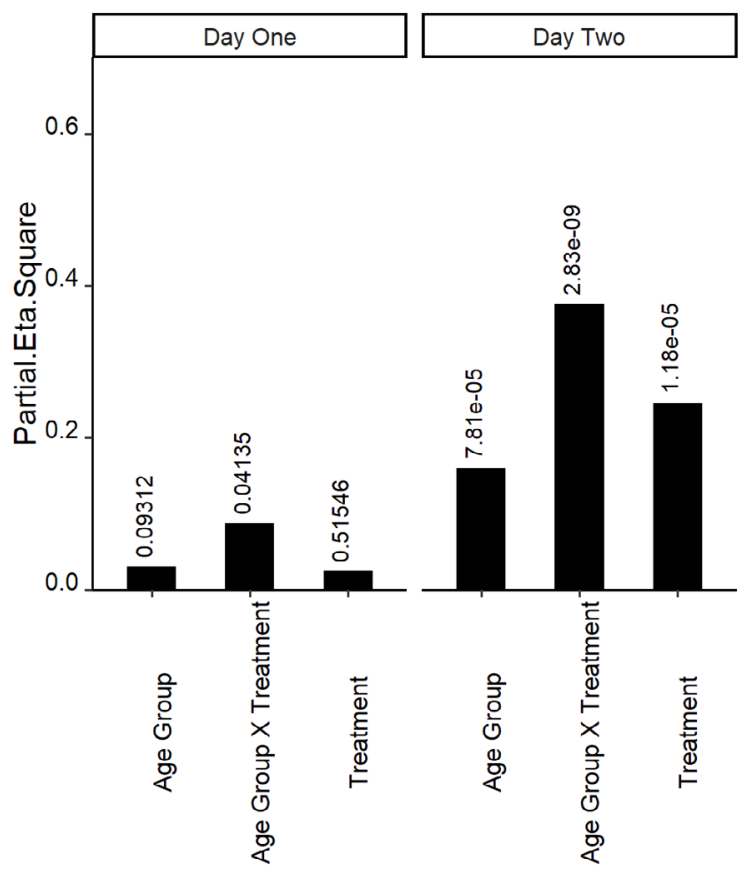

NEUR SCIENCE

Figure 1. Partial effect size of age and treatment alone or in combination on animals performance in Step-Through Latencies (STL) on day 1 and day 2

bination $\left[\mathrm{F}_{8,176}=7.6434, \mathrm{P}<0.001\right]$, could significantly influence the STL on day 2. In the following, the effects of treatment on STL were evaluated in each day separately.

On day 1 , the groups did not show significant differences among STL to the dark compartment (Figure 2A). On day 2 , there was a significant difference between old and young control animals' performance in STL, while there were no significant differences between young and old treatment groups. So, all old treatment groups spent significantly more time in the light compartment compared to the control one $(\mathrm{P}<0.001)$. There is no significant difference between young animal groups in STL performance (Figure 2B).

\subsection{Biochemical analyses}

Similar to behavioral assessments, the partial effect size of age and treatment, alone or in combination, were evaluated (Figure 3). Statistical analysis showed that age could affect SOD ( $\mathrm{P}=2 \mathrm{e}-16), \mathrm{GPx}(\mathrm{P}=2 \mathrm{e}-16)$, and CATA (8.4e-12) activity and MDA level $(\mathrm{P}=2 \mathrm{e}-16)$ and total antioxidant capacity $(\mathrm{P}=4.14 \mathrm{e}-13)$ in the hippocampus. The results demonstrated that treatments significantly affects SOD $(\mathrm{P}=8.69 \mathrm{e}-12), \mathrm{GPx}(\mathrm{P}=1.11 \mathrm{e}-13)$ and CATA $(\mathrm{P}=7.21 \mathrm{e}-09)$ activity, MDA level $(\mathrm{P}=9.74 \mathrm{e}-10)$ and total antioxidant capacity $(\mathrm{P}=2.05 \mathrm{e}-10)$. However, the combination of age and treatment (age group $\times$ treatment) could not affect any of the antioxidant factors except the MDA level $(\mathrm{P}=4.74 \mathrm{e}-07)$. On the other hand, independent variables of age $\left(\mathrm{F}_{5,45}=155.173, \mathrm{P}<0.001\right)$ and treatments $\left(\mathrm{F}_{20,192}=3.080, \mathrm{P}<0.001\right)$ alone or in combination $\left(\mathrm{F}_{20,192}=2.108, \mathrm{P}<0.01\right)$ could significantly influence the levels of TAC and MDA and also the activity of SOD, GPX, CATA in hippocampus.

\subsubsection{Superoxide Dismutase (SOD)}

As shown in Figure 4A, in the old animals, SOD enzyme activity significantly increased in each treatment group compared to the control $(\mathrm{P}<0.001$ for exercise and exercise/rosemary, $\mathrm{P}<0.01$ for rosemary). In contrast, no significant difference was observed in young groups of animals. Also, the comparison between young and old animal groups revealed significant increases in all young groups compared to similar old ones $(\mathrm{P}<0.001$ for the control and exercise/rosemary groups and $\mathrm{P}<0.05$ for the similar exercise groups), except for the rosemary groups.

\subsubsection{Glutathione Peroxidase (GPx)}

Figure 4B shows that in the old animals, GPx enzyme activity only increased significantly in the exercise/ rosemary group compared to the control $(\mathrm{P}<0.001)$. In comparison, no significant difference was seen among young groups of animals. Also, the comparison between young and old animal groups revealed significant increases in all young groups compared to similar old ones $(\mathrm{P}<0.001)$

\subsubsection{Catalase (CATA)}

As shown in Figure 4C, CATA enzyme activity in old animals significantly increased in treatment groups compared to the control group $(\mathrm{P}<0.05$ for exercise and $\mathrm{P}<0.001$ for exercise/rosemary). However, young groups of animals did not show significant differences. Comparison of the young and old animal groups revealed significant increases in all young groups compared to the similar old ones $(\mathrm{P}<0.001$ for the control and exercise/ rosemary groups and $\mathrm{P}<0.05$ for the similar exercise groups), except for the rosemary groups.

\subsubsection{Total Antioxidant Capacity (TAC)}

Evaluation of the TAC level in the hippocampus of old animals revealed significant increases in each treatment group $(\mathrm{P}<0.001$ for exercise and exercise/rosemary, $\mathrm{P}<0.01$ for rosemary) than the control group. Also, no significant difference was seen between young groups of animals. Based on the findings, there was no significant 


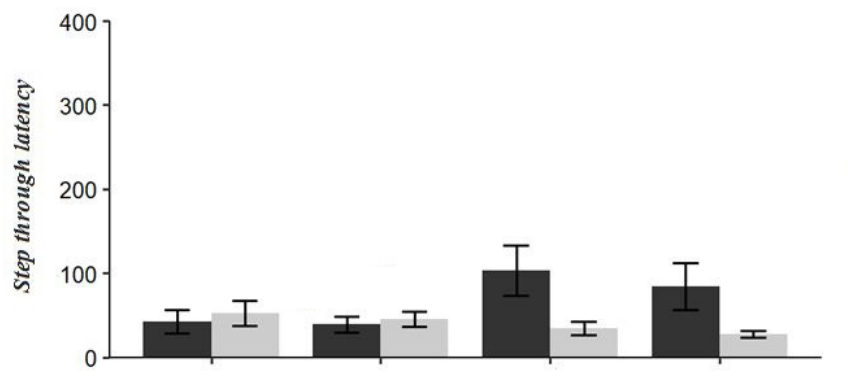

A

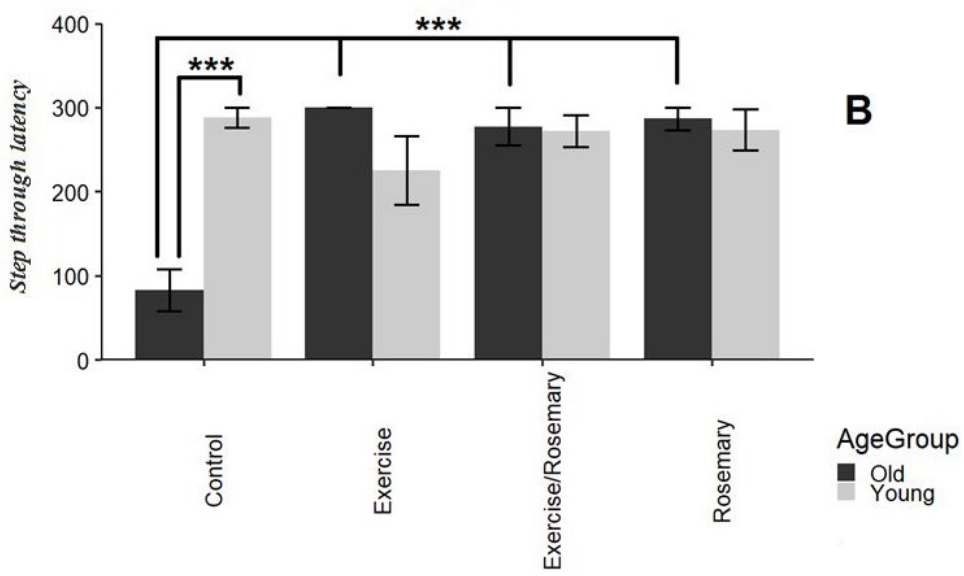

Figure 2. Step-through latency score in experimental groups (Mean \pm SEM), A: Day 1, and B: Day 2

NEUR SCIENCE

${ }^{* * t} \mathrm{P}<0.001$.

difference between old and young animals in all groups with similar conditions, except between the control groups $(\mathrm{P}<0.001)$ (Figure 4D).

\subsubsection{Malondialdehyde (MDA)}

For MDA levels, our results demonstrated significant decreases in the old treatment animals in comparison with the control group $(\mathrm{P}<0.001$ for exercise and exercise/rosemary groups, and $\mathrm{P}<0.01$ for rosemary). However, there was no significant difference between young animals. On the other hand, the levels of MDA in old animals were significantly more than that in young animals in similar groups $(\mathrm{P}<0.001)$ (Figure 4E).

3.3. Partial Pearson correlation test between enzymes and Step-Through Latency (STL) scores

As shown in Table 1, the Partial Pearson analysis test revealed a positive correlation between SOD enzyme activity and STL score on day $2(\mathrm{r}=0.389, \mathrm{P}<0.01)$. The TAC level showed a positive correlation with the STL score on day $2(\mathrm{r}=0.342, \mathrm{P}<0.05)$. While there were negative correlations between MDA levels and STL scores on both days $(\mathrm{r}=-0.271, \mathrm{P}<0.05$ : for the first day and $\mathrm{r}=$ $-0.573, \mathrm{P}<0.001$ for the second day).

\section{Discussion}

The aging process shows the cumulative effects of deterioration caused by free radicals in cells and tissues. Several studies have reported correlations between aging and the accumulation of oxidative damage in cells (Head, 2009; Posadas et al., 2009). In addition, a reduced cognitive ability, which occurs in normal aging, may result from oxidative damage in the hippocampus. Some studies suggest that working memory, long-term memory, and perceptual speed are reduced because of aging (Park et al., 2002). Furthermore, previous studies demonstrated that exercise could regulate several transcription factors involved in the electron transfer chain in mitochondria and causes enhancement in oxidation-sensitive transcription factors such as PGC-1 $\alpha$ (Peroxisome proliferator-activated receptor gamma coactivator 1-alpha) that plays a vital role in Reactive Oxygen Species (ROS) metabolism (Jacobson et al., 2008). Regular exercise, besides increasing Brain-Derived Neurotrophic Factor (BDNF) in the hippocampus, enhanced Vascular Endothelial Growth Factor (VEGF) production, which improves brain blood circulation (van Praag, Shubert, Zhao \& Gage, 2005; Radak, Kumagai, Taylor, Naito \& Goto, 2007). 


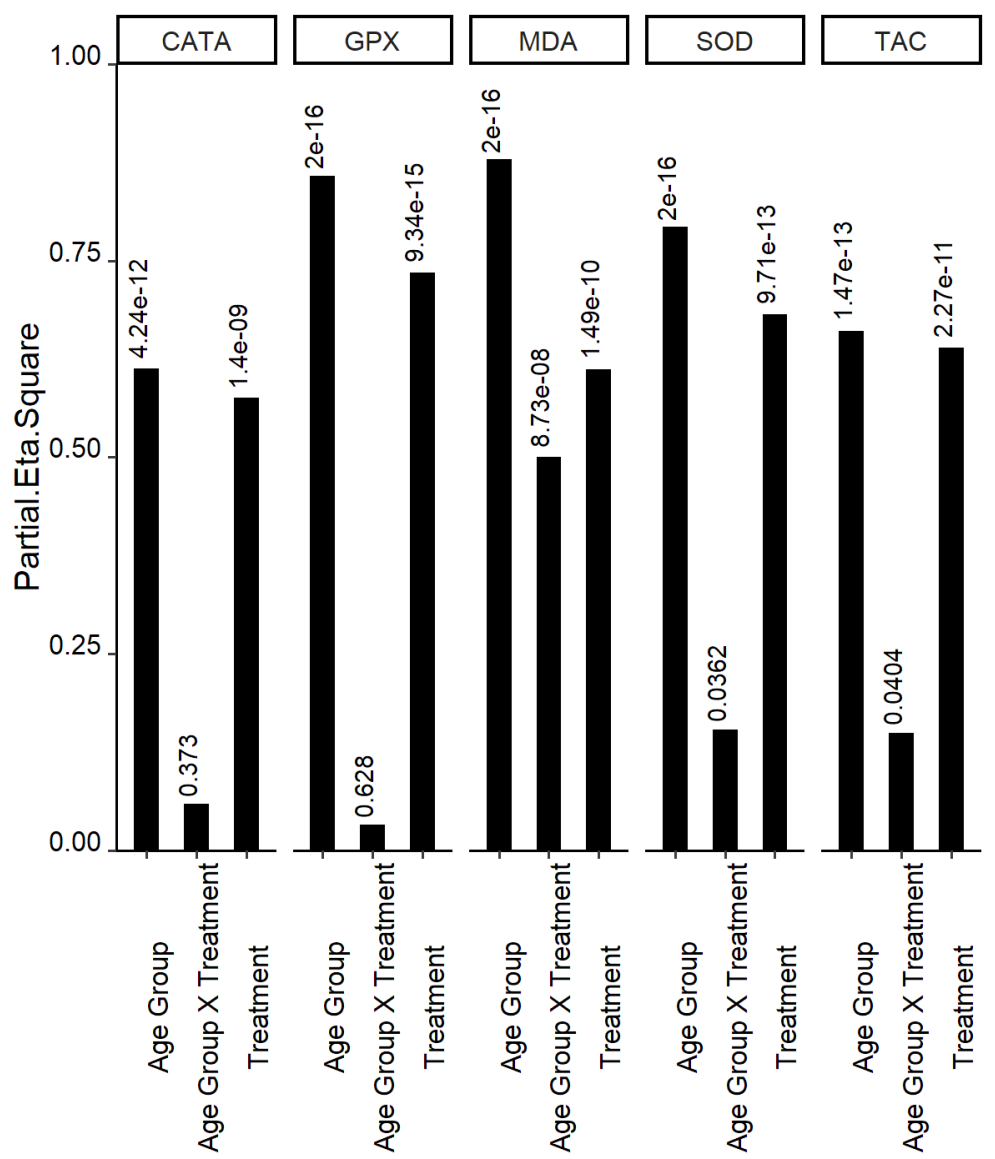

NEUR SCIENCE

Figure 3. Partial effect size of age and treatment alone or in combination on Superoxide Dismutase (SOD), Glutathione Peroxidase (Gpx) and Catalase (CATA) enzymes activity, Total Antioxidant Capacity (TAC), and Malondialdehyde (MDA) levels

Exercise improves cognitive functions and delays the onset of Alzheimer disease (Rovio et al., 2005). In a recent study, moderate treadmill exercise $(20 \mathrm{~min} / \mathrm{d})$ for 4 weeks decreased GFAP (glial fibrillary acidic protein) and NO (nitric oxide), but increased glutamine synthesis in the hippocampus (Bernardi et al., 2013). Rosmarinus officinalis extract contains several antioxidant compounds, polyphenols, diterpenes, exhibiting different properties, such as hepatoprotective, anti-hyperglycemic, anti-ulcerogenic, and photo-protection effects (Corrêa Dias, Foglio, Possenti \& de Carvalho, 2000; Sotelo-Félix et al., 2002; Kumar, Subramaniyan \& Thiruvengadam, 2013; Pérez-Sánchez et al., 2014). Also, rosemary extract consumption by old rats decreased catalase activity, lipid peroxidation, and ROS levels in the cerebrum (Posadas et al., 2009).

In the present study, we examined learning and working memory using the shuttle box in old and young rats treated with daily $100 \mathrm{mg} / \mathrm{kg}$ rosemary extract and FAE over 12 weeks. In the PA test, STL data showed that old animals in the control group spent less time in the light compartment than young animals on this day of the test with the same conditions. On the other hand, the performances of old and young animals, which received treatments (exercise and rosemary, alone or in combination) were similar on the second day of the PA test. These data reveal that aging can decrease learning and memory, but exercise like the administration of rosemary extract can improve these functions. This finding means that exercise and rosemary, alone or in combination, improve the PA learning ability of old animals and help them function like the young ones.

Many studies have shown that exercise activities have mental health benefit (Deslandes et al., 2009). Exercise can improve brain function by regulating growth factors and reducing risk factors (Cotman et al., 2007). It is suggested that Insulin-like Growth Factor 1 (IGF-1) and BDNF pathways are important targets during exercise. Blocking hippocampal receptors for IGF-1 (IGF-1R) or BDNF (TrkB) can eliminate the effectiveness of exercise on hippocampal plasticity and increase some molecules, including synapsin 1 , calcium/calmodulin-dependent ki- 
Table 1. Partial Pearson correlation between enzymes and Step-Through Latency (STL) scores

\begin{tabular}{ccc}
\hline Enzyme/Level & Pearson Correlation & STL (Day 1) / STL (Day 2) \\
\hline Superoxide dismutase & Correlation & $0.189 / 0.389$ \\
\hline Glutathione peroxidase & Significance (2-tailed) & $0.167 / 0.003^{* *}$ \\
& Correlation & $-0.022 / 0.141$ \\
\hline Catalase & Significance (2-tailed) & $0.875 / 0.304$ \\
\hline Cotal Antioxidant Capacity & Correlation & $0.012 / 0.185$ \\
& Significance (2-tailed) & $0.931 / 0.185$ \\
\hline Malondialdehyde & Correlation & $0.140 / 0.342$ \\
& Significance (2-tailed) & $0.307 / 0.011^{*}$ \\
& Correlation & $-0.271 /-0.573$ \\
\hline
\end{tabular}

${ }^{*} \mathrm{P}<0.05 ;{ }^{* * \mathrm{P}<0.01 ;}$ *** $\mathrm{P}<0.001$.

NEUR SCIENCE

nase II, and mitogen-activated protein kinase II (Vaynman, Ying \& Gomez-Pinilla, 2004; Ding, Vaynman, Akhavan, Ying \& Gomez-Pinilla, 2006; Kaliman et al., 2011). Lower neurogenesis in the hippocampus is associated with cognitive decline (Drapeau et al., 2003), whereas exercise enhances neurogenesis, contributing to improved cognitive functions (van Praag, Christie, Sejnowski \& Gage, 1999; van Praag et al., 2005).

The previous studies revealed that memory deficits (tested by PA learning task) caused by morphine in rats were improved with acute treadmill running ( 2 hours at 5 $\mathrm{m} / \mathrm{min}$ for 10 days) (Alaei et al., 2006). Exercise by the treadmill (30 $\mathrm{min} / \mathrm{d}$ for 6 weeks, with a maximum speed of $8 \mathrm{~m} / \mathrm{min}$ ) also increased neurogenesis and both spatial and short-term memory functions and suppressed apoptosis in the dentate gyrus in old rats but not in young rats (Kim et al., 2010). On the other hand, treadmill exercise $(1 \mathrm{~h} / \mathrm{d}, 5$ $\mathrm{d} / \mathrm{wk}$ ) for 4 weeks in preadolescence rats (4-6 weeks old) could facilitate PA performance, decrease 5-HT levels in the hippocampus, and reduce 5-HT1A receptor expression in the amygdala (Chen et al., 2008). Another study showed that carnosic acid could ameliorate spatial learning and memory impairments due to beta-amyloid toxicity of rats' hippocampus (Rasoolijazi et al., 2013).

Also, this study revealed that the levels of SOD, GPx, CATA, MDA enzymes, and TDC are low in the hippocampus of old control rats, but our treatments could change their levels. At the same time, rosemary could not change the level of CATA and GPx levels alone. Also, exercise could not change the level of GPx, alone.
However, the combination of exercise and rosemary could affect CATA and GPx, like the other ones. It is shown that exercise could be more effective than rosemary for changing the SOD, CATA, TAC, and MDA levels in old rats. Most probably, due to the current high level of antioxidant ability in the brain of young rats, no such improvement was observed in these animals.

Consistent with our results, it was shown that physical exercise improves TAC through modulation of Nerve Growth Factor (NGF) and Sirtuins (SIRT1 \& SIRT3) genes in 3- to 5-month-old male rats (Franzoni et al., 2017). Superoxide $\left(\mathrm{O}_{2}\right)$ is one of the most toxic molecules in the brain that should be neutralized and become less dangerous forms of oxygen $\left(\mathrm{O}_{2}+\mathrm{H}_{2} \mathrm{O}_{2}\right)$ by the SOD enzyme (Musalmah, Fairuz, Gapor \& Ngah, 2002; Ishrat et al., 2006). Also, it was indicated that long-term exercise treatment significantly increases the SOD enzyme activity in 12-month-old rats compared to the control group (Marosi et al., 2012), resulting in the removal of $\mathrm{H}_{2} \mathrm{O}_{2}$ by CATA and GPx enzymes (Ishrat et al., 2006).

Similar to our results for these enzymes, another study showed some improvement in GPx and CATA activity following sumac extract administration among 25-month-old rats than the control group (Abbass, Mahmoud, Hussein \& Gabr, 2012). It was shown the same increase in antioxidant enzymes in the spleen and liver tissues in quails due to rosemary treatment (Bulbul, Bulbul, Biricik, Yesilbag \& Gezen, 2012), which is consistent with our findings. Posadas et al. also suggested that the rosemary extract has efficacy on the activity of the 


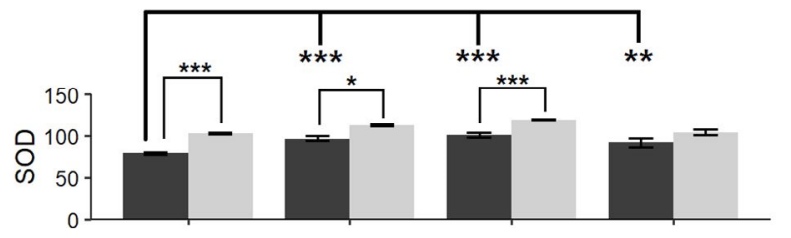

A
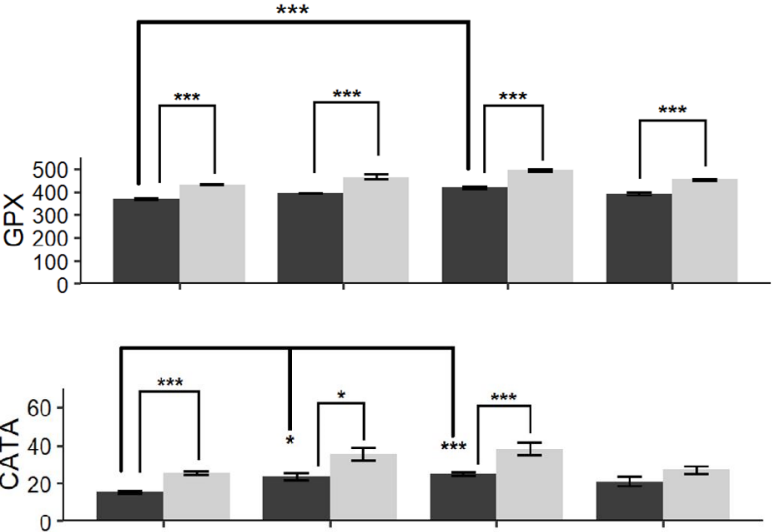

D

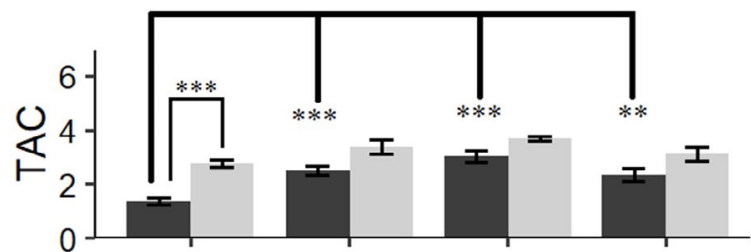

$\mathbf{E}$

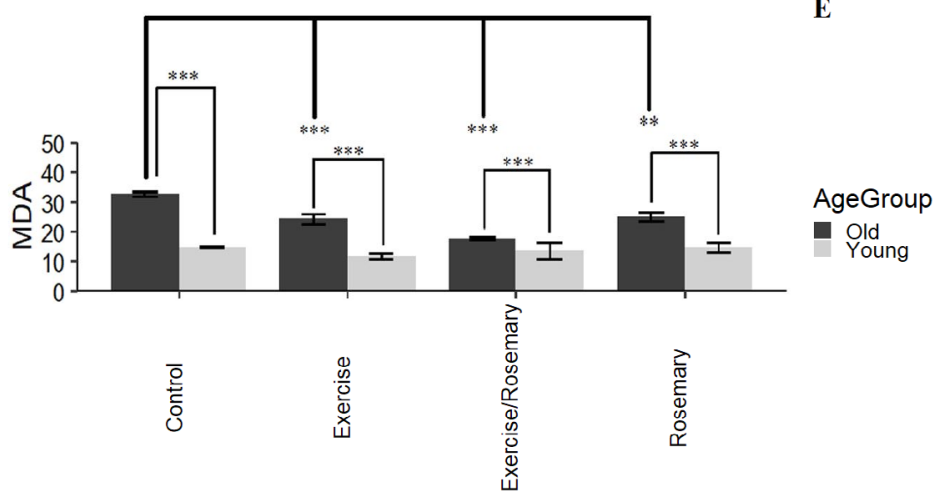

Figure 4. Intragroup comparisons for antioxidant enzyme activities

NEUR $\$$ SCIENCE

A: For Superoxide Dismutase (SOD); B: Glutathione Peroxidase (Gpx); and C: Catalase (CATA); also D: The evaluation of Total Antioxidant Capacity (TAC); and E: Malondialdehyde (MDA) levels in the hippocampus in old and young animals in different groups (Mean \pm SEM).

${ }^{*} \mathrm{P}<0.05,{ }^{, *} \mathrm{P}<0.01,{ }^{*+*} \mathrm{P}<0.001$.

antioxidant enzymes in the brain tissue of old rats (Posadas et al., 2009). Results of another study showed that the rosemary extract could increase antioxidant enzyme activity in the hippocampus and also reduces the MDA level in rats (Rasoolijazi et al., 2015).

Oxidative damage to lipids and proteins causes alteration in cell membrane structures, decreases the activity of enzymes, and leads to cell death (Niki, 2008; Man- sour \& Mossa, 2009). This index correlates with aging in some organs, such as the brain and liver. At the same time, there is no association in the heart and lungs for these factors (Péréz, López \& de Quiroga, 1991). On the other hand, the results of the examination of the peroxidation of lipids on the liver of old male and female rats demonstrated that the MDA levels of the liver increased $50 \%$ in old rats compared to younger animals, while the MDA level was 50\% lower than younger animals in fe- 
males. As a result, they suggested that the MDA level depends on the sex and age of these animals (Rikans \& Roger Hornbrook, 1997). Furthermore, exercise and vitamin E dietary could significantly increase the activity of oxidative enzymes (CATA, GPx, SOD) and also cause significant reduction of MDA levels in the hippocampus in middle-aged rats (Asha Devi \& Ravi Kiran, 2004)

The present study shows that daily administration of $100 \mathrm{mg} / \mathrm{kg}$ rosemary extract and FAE on a treadmill $(1 \mathrm{~h} / \mathrm{d})$ for 3 months could improve working memory evaluated by shuttle box task in old rats. Measuring antioxidants enzyme activity, SOD, TAC, and MDA levels confirmed the results of the behavioral tests. These results may partly be due to the effects of aerobic activity on improving the efficiency of the capillary system, which triggers the plasticity in the hippocampus, and the antioxidant activity of rosemary extract.

\section{Conclusion}

Using the natural antioxidants in the diet or doing aerobic exercises every day may effectively prevent the decline of cognitive functions, which occurs through the aging process due to oxidative stress in rats.

\section{Ethical Considerations}

\section{Compliance with ethical guidelines}

The animal experiments were carried out according to the Ethics Committee of IUMS (Ethical code: IR.IUMS. REC.1393.24834) to use laboratory animals (following the National Institutes of Health Guide for Care and Use of Laboratory Animals: NIH Publication 1996). The efforts were made to minimize unnecessary pain and suffering within labs.

\section{Funding}

This project was supported financially by the grant (Code: 93-02-30-24834) by the Iran University of Medical Sciences, Tehran, Iran.

\section{Authors' contributions}

Investigation, writing - original draft: Homa Rasoolijazi; Data analysis: Sattar Norouzi Ofogh; Funding acquisition and resources: Shima Ababzadeh, Mehdi Mehdizadeh, and Fatemeh Shabkhiz; Approving the final version for publication: All authors.

\section{Conflict of interest}

The authors declared no conflict of interest.

\section{References}

Abbass, M. M., Mahmoud, A. H., Hussein, M. M. A., \& Gabr, S. A. (2012). Assessment of antioxidant changes of aged rats treated with sumac extract. Journal of American Science, 8(4), 553-8. http://www.jofamericanscience.org/journals/amsci/am0804/073_8499am0804_553_558.pdf

Aebi, H. (1984). [13] Catalase in vitro. In L. Packer (Ed.), Oxygen radicals in biological systems. Methods in enzymology (pp. 121-126). Vol. 105. Amsterdam: Elsevier. [DOI:10.1016/S00766879(84)05016-3]

Alaei, H., Borjeian, L., Azizi, M., Orian, Sh., Pourshanazari, A. A. \& Hanninen, O. (2006). Treadmill running reverses retention deficit induced by morphine. European Journal of Pharmacology, 536(1-2), 138-41. [DOI:10.1016/j.ejphar.2006.02.025] [PMID]

Asha Devi, S., \& Ravi Kiran, T. (2004). Regional responses in antioxidant system to exercise training and dietary vitamin E in aging rat brain. Neurobiology of Aging, 25(4), 501-8. [DOI:10.1016/S0197-4580(03)00112-X]

Azad, N., Rasoolijazi, H., Joghataie, M. T., \& Soleimani, S. (2011) Neuroprotective effects of carnosic acid in an experimental model of Alzheimer's disease in rats. Cell Journal (Yakhteh), 13(1), 39-44. [PMID] [PMCID]

Balu, D. T., \& Lucki, I. (2009). Adult hippocampal neurogenesis: Regulation, functional implications, and contribution to disease pathology. Neuroscience \& Biobehavioral Reviews, 33(3), 232-52. [DOI:10.1016/j.neubiorev.2008.08.007] [PMID] [PMCID]

Bernardi, C., Tramontina, A. C., Nardin, P., Biasibetti, R., Costa A. P., \& Vizueti, A. F., et al. (2013). Treadmill exercise induces hippocampal astroglial alterations in rats. Neural Plasticity, 2013, 709732. [DOI:10.1155/2013/709732] [PMID] [PMCID]

Bulbul, A., Bulbul, T., Biricik, H., Yesilbag, D., \& Gezen, S. S. (2012). Effects of various levels of rosemary and oregano volatile oil mixture on oxidative stress parameters in quails. African Journal of Biotechnology, 11(8), 1800-5. [DOI:10.5897/AJB11.2605]

Chen, H. I., Lin, L. Ch., Yu, L., Liu, Y. F., Kuo, Y. M., \& Huang, A M., et al. (2008). Treadmill exercise enhances passive avoidance learning in rats: The role of down-regulated serotonin system in the limbic system. Neurobiology of Learning and Memory, 89(4), 489-96. [DOI:10.1016/j.nlm.2007.08.004] [PMID]

Corrêa Dias, P., Foglio, M. A., Possenti, A., \& de Carvalho, J. E. (2000). Antiulcerogenic activity of crude hydroalcoholic extract of Rosmarinus officinalis L. Journal of Ethnopharmacology, 69(1), 57-62. [DOI:10.1016/S0378-8741(99)00133-6]

Cotman, C. W., Berchtold, N. C., \& Christie, L. A. (2007). Exercise builds brain health: Key roles of growth factor cascades and inflammation. Trends in Neurosciences, 30(9), 464-72. [DOI:10.1016/j.tins.2007.06.011] [PMID] 
de Oliveira, M. R. (2018). Carnosic acid as a promising agent in protecting mitochondria of brain cells. Molecular Neurobiology 55(8), 6687-99. [DOI:10.1007/s12035-017-0842-6] [PMID]

Deslandes, A., Moraes, H., Ferreira, C., Veiga, H., Silveira, H., \& Mouta, R., et al. (2009). Exercise and mental health: Many reasons to move. Neuropsychobiology, 59(4), 191-8. [DOI:10.1159/000223730] [PMID]

Ding, Q., Vaynman, S., Akhavan, M., Ying, Z., \& Gomez-Pinilla, F. (2006). Insulin-like growth factor I interfaces with brain-derived neurotrophic factor-mediated synaptic plasticity to modulate aspects of exercise-induced cognitive function. Neuroscience, 140(3), 823-33. [DOI:10.1016/j.neuroscience.2006.02.084] [PMID]

Drapeau, E., Mayo, W., Aurousseau, C., Le Moal, M., Piazza, P. V., \& Abrous, D. N. (2003). Spatial memory performances of aged rats in the water maze predict levels of hippocampal neurogenesis. Proceedings of the National Academy of Sciences, 100(24), 14385-90. [DOI:10.1073/pnas.2334169100] [PMID] [PMCID]

Franzoni, F., Federighi, G., Fusi, J., Cerri, E., Banducci, R., \& Petrocchi, A., et al. (2017). Physical exercise improves total antioxidant capacity and gene expression in rat hippocampal tissue. Archives Italiennes de Biologie, 155(1/2), 1-10. [DOI:10.12871/000398292017121] [PMID]

Head, E. (2009). Oxidative damage and cognitive dysfunction Antioxidant treatments to promote healthy brain aging. Neurochemical Research, 34(4), 670-8. [DOI:10.1007/s11064-0089808-4] [PMID] [PMCID]

Hirsh, R. (1974). The hippocampus and contextual retrieval of information from memory: A theory. Behavioral Biology, 12(4), 421-44. [DOI:10.1016/S0091-6773(74)92231-7]

Hung, C. W., Chen, Y. Ch., Hsieh, W. L., Chiou, Sh. H., \& Kao, Ch. L. (2010). Ageing and neurodegenerative diseases. Ageing Research Reviews, 9(Suppl), S36-46. [DOI:10.1016/j. arr.2010.08.006] [PMID]

Ishrat, T., Khan, M. B., Hoda, M. N., Yousuf, S., Ahmad, M., \& Ansari, M. A., et al. (2006). Coenzyme Q10 modulates cognitive impairment against intracerebroventricular injection of streptozotocin in rats. Behavioural Brain Research, 171(1), 9-16. [DOI:10.1016/j.bbr.2006.03.009] [PMID]

Jacobson, L., Zhang, R., Elliffe, D., Chen, K. F., Mathai, S., \& McCarthy, D., et al. (2008). Correlation of cellular changes and spatial memory during aging in rats. Experimental Gerontology, 43(10), 929-38. [DOI:10.1016/j.exger.2008.08.002] [PMID]

Kaliman, P., Párrizas, M., Lalanza, J. F., Camins, A., Escorihuela, R. M., \& Pallàs, M. (2011). Neurophysiological and epigenetic effects of physical exercise on the aging process. Ageing Research Reviews, 10(4), 475-86. [DOI:10.1016/j.arr.2011.05.002] [PMID]

Kei, S. (1978). Serum lipid peroxide in cerebrovascular disorders determined by a new colorimetric method. Clinica Chimica acta, 90(1), 37-43. [DOI:10.1016/0009-8981(78)90081-5]

Kim, S. E., Ko, I. G., Kim, B. K., Shin, M. S., Cho, S., Kim, Ch. J., et al. (2010). Treadmill exercise prevents aging-induced failure of memory through an increase in neurogenesis and suppression of apoptosis in rat hippocampus. Experimental Gerontology, 45(5), 357-65. [DOI:10.1016/j.exger.2010.02.005] [PMID]
Kumar, M., Subramaniyan, J., \& Thiruvengadam, D. (2013). Geraniol, a component of plant essential oils prevents experimental oral carcinogenesis by modulating glycoprotein abnormalities and membrane bound ATPase's. International Journal of Pharmacy and Pharmaceutical Sciences, 1(5), 416-21. https://www.researchgate. net/publication/265686901

Lau, F. C., Shukitt-Hale, B., \& Joseph, J. A. (2005). The beneficial effects of fruit polyphenols on brain aging. Neurobiology of Aging, 26 Suppl 1, 128-32. [DOI:10.1016/j.neurobiolaging.2005.08.007] [PMID]

Mansour, S. A., \& Mossa, A. T. H. (2009). Lipid peroxidation and oxidative stress in rat erythrocytes induced by chlorpyrifos and the protective effect of zinc. Pesticide Biochemistry and Physiology, 93(1), 34-9. [DOI:10.1016/j.pestbp.2008.09.004]

Marosi, K., Bori, Z., Hart, N., Sárga, L., Koltai, E., \& Radák, Z., et al. (2012). Long-term exercise treatment reduces oxidative stress in the hippocampus of aging rats. Neuroscience, 226, 21-8. [DOI:10.1016/j.neuroscience.2012.09.001] [PMID]

Mattson, M. P., \& Magnus, T. (2006). Ageing and neuronal vulnerability. Nature Reviews Neuroscience, 7(4), 278-94. [DOI:10.1038/ nrn1886] [PMID] [PMCID]

Miller, N. J., Rice-Evans, C., Davies, M. J., Gopinathan, V., \& Milner, A. (1993). A novel method for measuring antioxidant capacity and its application to monitoring the antioxidant status in premature neonates. Clinical Science, 84(4), 407-12. [DOI:10.1042/cs0840407] [PMID]

Misra, H. P., \& Fridovich, I. (1972). The role of superoxide anion in the autoxidation of epinephrine and a simple assay for superoxide dismutase. The Journal of Biological Chemistry, 247(10), 3170-5. [DOI:10.1016/S0021-9258(19)45228-9]

Munné-Bosch, S., \& Alegre, L. (2001). Subcellular compartmentation of the diterpene carnosic acid and its derivatives in the leaves of rosemary. Plant Physiology, 125(2), 1094-102. [DOI:10.1104/ pp.125.2.1094] [PMID] [PMCID]

Musalmah, M., Fairuz, A. H., Gapor, M. T., \& Ngah, W. Z. W. (2002). Effect of vitamin $\mathrm{E}$ on plasma malondialdehyde, antioxidant enzyme levels and the rates of wound closures during wound healing in normal and diabetic rats. Asia Pacific Journal of Clinical Nutrition, 11(s7), S448-51. [DOI:10.1046/j.1440-6047.11.s.7.6.x] [PMID]

Naderali, E., Nikbakht, F., Ofogh, S. N., \& Rasoolijazi, H. (2018) The role of rosemary extract in degeneration of hippocampal neurons induced by kainic acid in the rat: A behavioral and histochemical approach. Journal of Integrative Neuroscience, 17(1), 31-43. [DOI:10.3233/JIN-170035]

Newgard, Ch. B., \& Sharpless, N. E. (2013). Coming of age: Molecular drivers of aging and therapeutic opportunities. The Journal of Clinical Investigation, 123(3), 946-50. [DOI:10.1172/JCI68833] [PMID] [PMCID]

Niki, E. (2008). Lipid peroxidation products as oxidative stress biomarkers. BioFactors, 34(2), 171-80. [DOI:10.1002/biof.5520340208] [PMID]

Park, D. C., Lautenschlager, G., Hedden, T., Davidson, N. S., Smith A. D., \& Smith, P. K. (2002). Models of visuospatial and verbal memory across the adult life span. Psychology and Aging, 17(2), 299-320. [DOI:10.1037/0882-7974.17.2.299] [PMID]

Pérez-Sánchez, A., Barrojón-Catalán, E., Caturla, N., Catillo, J., Benavente-García, O., \& Alcaraz, M., et al. (2014). Protective effects of citrus and rosemary extracts on UV-induced damage in skin cell model and human volunteers. Journal of Photochemistry and Photobiology B: Biology, 136, 12-8. [DOI:10.1016/j.jphotobiol.2014.04.007] [PMID] 
Péréz, R., López, M., \& de Quiroga, G. B. (1991). Aging and lung antioxidant enzymes, glutathione, and the lipid peroxidation in the rat. Free Radical Biology and Medicine, 10(1), 35-9. [DOI:10.1016/08915849(91)90019-Y]

Perry, N. S. L., Menzies, R., Hodgson, F., Wedgewood, P., Howes, M. R., \& Brooker, H. J., et al. (2018). A randomised double-blind placebo-controlled pilot trial of a combined extract of sage, rosemary and melissa, traditional herbal medicines, on the enhancement of memory in normal healthy subjects, including influence of age. Phytomedicine, 39, 42-8. [DOI:10.1016/i.phymed.2017.08.015] [PMID]

Posadas, S. J., Caz, V, Largo, C, De la Gándara, B, Matallanas, B \& Reglero, G., et al. (2009). Protective effect of supercritical fluid rosemary extract, Rosmarinus officinalis, on antioxidants of major organs of aged rats. Experimental Gerontology, 44(6-7), 383-9. [DOI:10.1016/j.exger.2009.02.015] [PMID]

Radak, Z., Kumagai, Sh., Taylor, A. W., Naito, H., \& Goto, S. (2007) Effects of exercise on brain function: Role of free radicals. Applied Physiology, Nutrition, and Metabolism, 32(5), 942-6. [DOI:10.1139/ H07-081] [PMID]

Rasoolijazi, H., Azad, N., Joghataie, M. T., Kerdari, M., Nikbakht, F, \& Soleimani, M. (2013). The protective role of carnosic acid against beta-amyloid toxicity in rats. The Scientific World Journal, 2013, 917082. [DOI:10.1155/2013/917082] [PMID] [PMCID]

Rasoolijazi, H., Mehdizadeh, M., Soleimani, M., Nikbakhte, F., Eslami Farsani, M., \& Ababzadeh, Sh. (2015). The effect of rosemary extract on spatial memory, learning and antioxidant enzymes activities in the hippocampus of middle-aged rats. Medical Journal of the Islamic Republic of Iran, 29(1), 225-35. http://mjiri.iums.ac.ir/ article-1-2736-en.html

Rikans, L. E., \& Roger Hornbrook, K. (1997). Lipid peroxidation, antioxidant protection and aging. Biochimica et Biophysica Acta (BBA) - Molecular Basis of Disease, 1362(2-3), 116-27. [DOI:10.1016/S09254439(97)00067-7]

Rovio, S., Kåreholt, I,. Helkala, E. L., Viitanen, M., Winblad, B, \& Tuomilehto, J., et al. (2005). Leisure-time physical activity at midlife and the risk of dementia and Alzheimer's disease.The Lancet Neurology, 4(11), 705-11. [DOI:10.1016/S1474-4422(05)70198-8]

Sharman, E. H., Bondy, S. C., Sharman, K. G., Lahiri, D., Cotman, C. W., \& Perreau, V. M. (2007). Effects of melatonin and age on gene expression in mouse CNS using microarray analysis. Neurochemistry International, 50(2), 336-44. [DOI:10.1016/j.neuint.2006.09.001] [PMID] [PMCID]

Shi, Y., Buffenstein, R., Pulliam, D. A., \& Van Remmen, H. (2010) Comparative studies of oxidative stress and mitochondrial function in aging. Integrative and Comparative Biology, 50(5), 869-79. [DOI:10.1093/icb/icq079] [PMID]

Silva, R. H., Felicio, L. F., \& Frussa-Filho, R. (1999). Ganglioside GM1 attenuates scopolamine-induced amnesia in rats and mice. Psychopharmacology, 141(2), 111-7. [DOI:10.1007/s002130050814] [PMID]

Sotelo-Félix, J. I., Martinez-Fong, D., Muriel, P., Santillán, R. L. Castillo, D., \& Yahuaca, P. (2002). Evaluation of the effectiveness of Rosmarinus officinalis (Lamiaceae) in the alleviation of carbon tetrachloride-induced acute hepatotoxicity in the rat. Journal of Ethnopharmacology, 81(2), 145-54. [DOI:10.1016/ S0378-8741(02)00090-9]

van Praag, H. (2008). Neurogenesis and exercise: Past and future directions. NeuroMolecular Medicine, 10(2), 128-40. [DOI:10.1007/ s12017-008-8028-z] [PMID] van Praag, H., Christie, B. R., Sejnowski, T. J., \& Gage, F. H. (1999). Running enhances neurogenesis, learning, and longterm potentiation in mice. Proceedings of the National Academy of Sciences, 96(23), 13427-31. [DOI:10.1073/pnas.96.23.13427] [PMID] [PMCID]

van Praag, H., Shubert, T., Zhao, Ch., \& Gage, F. H. (2005). Exercise enhances learning and hippocampal neurogenesis in aged mice. Journal of Neuroscience, 25(38), 8680-5. [DOI:10.1523/ JNEUROSCI.1731-05.2005] [PMID] [PMCID]

Vaynman, Sh., Ying, Zh., \& Gomez-Pinilla, F. (2004). Hippocampal BDNF mediates the efficacy of exercise on synaptic plasticity and cognition. European Journal of Neuroscience, 20(10), 2580-90. [DOI:10.1111/j.1460-9568.2004.03720.x] [PMID]

Wheeler, C. R., Salzman, J. A., Elsayed, N. M., Omaye, S. T., \& Korte Jr, D. W. (1990). Automated assays for superoxide dismutase, catalase, glutathione peroxidase, and glutathione reductase activity. Analytical Biochemistry, 184(2), 193-9. [DOI:10.1016/0003-2697(90)90668-Y]

Zhang, Y., Smuts, J. P., Dodbiba, E., Rangarajan, R., Lang, J. C., \& Armstrong, D. W. (2012). Degradation study of carnosic acid, carnosol, rosmarinic acid, and rosemary extract (Rosmarinus officinalis L.) assessed using HPLC. Journal of Agricultural and Food Chemistry, 60(36), 9305-14. [DOI:10.1021/jf302179c] [PMID]

Zheng, W., \& Wang, Sh. Y. (2001). Antioxidant activity and phenolic compounds in selected herbs. Journal of Agricultural and Food Chemistry, 49(11), 5165-70. [DOI:10.1021/jf010697n] [PMID]

Zhu, Y., Demidov, O. N., Goh, A. M., Virshup, D. M., Lane, D. P., \& Bulavin, D. V. (2014). Phosphatase WIP1 regulates adult neurogenesis and WNT signaling during aging. The Journal of Clinical Investigation, 124(7), 3263-73. [DOI:10.1172/JCI73015] [PMID] [PMCID] 